bacteria in a mixed culture composed of brine, and the persistence of cocci and torulæ; food by the feeding of ameba bacterially or acetic organisms with alcohol; reaction by the development of the lactic organisms in milk and the eradication of its associates; temperature by a combination in the growth of tubercle bacilli with saprophytes which will not grow at moderate temperature. Those fundamental biological requirements favor some forms of life association, while antagonizing others. Taken in conjunction with metabolic products as alcohol, lactic acid, acetic acid, amino-acids, ammonium, toxins and the many others that are possible, these biological factors offer a wide range of association, and at the same time determine the limitations.

Our experiences support these views, for involution forms or distorted morphology is easily traceable to one or more factors mentioned, and in the functioning processes of microorganisms how easy it is to alter the metabolic products and even the form by the addition or omission of an element. These acts have become an unconscious procedure and we do not, as a rule, make the subject one of systematic inquiry.

The association of animal and animal, or animal and plant, or plant and plant, when carried to comparatively loose social relations will in large part support this interpretation of these more intimate associations, illustrated through the channel of microorganisms. Animal life becomes adjusted to certain plants or other animal life, and is dependent upon their existence; plants depend upon animals and other plants; into which social relations enter the factors of food, temperature, and the other life conditions which apply to all living forms. Since this seems a fact so well established, and our work as microbiologists leads into the affairs of so many organisms which instigate numerous diverse ehangeschanges in some instances which are instituted by associational growth and which may affect their morphology, culture and physiology - it is pertinent in our researches to consider an organism in its natural microbial associations as significant as in a laboratory pure culture. Such factors should be directive for purposes of identification, study and application, since they suggest those possibilities which may be bound up in the intra- and inter-molecular relationships and reactions that dominate associations and individuals.

Charles E. Marshatl

Massachusetts Agricultural College, Amererst, Mass.

\section{DR. A. F. A. KING ON MOSQUITOES AND MALARIA 1}

Muor as I might wish to write of Dr. King as a personal friend, as a great teacher, as a big, broad, warm-hearted human, in all of which rôles I knew him well, it has seemed best to your committee that $I$ should confine my consideration to the single episode in the career of this many-sided man which relates to mosquitoes and malaria.

Dr. King was a deep thinker. He was not satisfied with even the generally accepted and apparently well founded views of men of science and of his own profession without a careful consideration and an ingenious twisting and testing of argument. This quality of mind he showed in a marked degree during the years 1881 and 1882 when he was filled with the thoughts of malaria and its probable origin and transmission. He never told me how or when the idea came to him that mosquitoes were transmitters of this disease. His search of the literature probably followed a fairly well worked out argument originating in his own mind. Surely he considered the idea as original when he came, probably late in 1881, to the laboratory of the late

1 Read at the memorial meeting for Dr. A. F. A. King of the Medical Society of the District of CoIumbia, Washington, January 20, 1915. 
Dr. C. V. Riley, my former chief and predecessor in office, and talked over the idea with Riley and myself. Shame to the short-sightedness of the two of us, that we rather scouted the idea, while giving him the information on mosquito biology which he afterwards incorporated in paragraph No. 1 of his published brief.

His argument was fully elaborated and his full paper was prepared early in 1882 and was read before the Philosophical Society of Washington, February 10 of that year, under the title "The Prevention of Malarial Disease Illustrating inter alia the Conservative Function of Ague." This meeting of the Philosophical Society was attended by forty-two members and visitors, and Dr. King's paper was discussed by Dr. J. S. Billings, Professor Doolittle, Dr. Toner and Dr. Antisell. No record was made of what was said in discussion except the following:

Mr. Billings remarked that since ague did not invariably result from insect bites, the most that could be claimed was that they accomplished an accidental inoculation with malarial poison. ${ }^{2}$

This statement is rather ambiguous and does not indicate what Dr. Billings really thought of Dr. King's paper.

The paper in its full form was never published, but in The Popular Science Monthly for September, 1883, Vol. XXIII., pages 644658, appears an article entitled "Insects and Disease-Mosquitoes and Malaria," which in a footnote is said to have been an abstract of the Philosophical Society paper. It is upon this published abstract that the scientific world's knowledge of King's views is based. Since the discussion in Riley's office, he had made a careful study of the literature and had found references to several early suggestions as to the possible carriage of disease by insects or as to the cause of disease by insect bites. His arguments are displayed in connection with mineteen propositions or series of facts with regard to the so-called malarial

2 Bulletin of the Philosophical Society of Washington, Vol. VI. (containing the minutes of the society for the year 1883, etc.), published 1884, page 10. poison. These facts were derived from different sources, but most of them were quoted from a paper read by Dr. John T. Metcalf, United States Sanitary Commission, 1862. Not all of these nineteen paragraphs are of equal force; and it has become the custom of writers in referring to King's paper to reduce them practically to the following:

1. The malarial season corresponds to the season of mosquito abundance.

2. Malarial country is suitable for mosquito breeding.

3. Similar conditions afford protection against malaria and against mosquitoes.

4. Exposure to night air means exposure to mosquitoes.

5. Influence of occupation. Soldiers, tramps and fishermen are particularly susceptible to malaria and are especially exposed to mosquitoes at night.

6. Turning up the soil or making excavations in previously healthy districts is often followed by malaria, but this turning up of the soil gives opportunities for water to accumulate and thus for mosquitoes to breed.

7. Coincidence of malaria and mosquito abundance-increase of both in late summer and early autumn.

But this summary gives but a faint idea of the value of The Popular Science Monthly paper. The reasoning throughout is close and convincing, and additional important points are brought out. For example,

"Malaria has an affinity for dense foliage, which has the power of accumulating it when lying in the course of winds blowing from malarious localities," and mosquitoes accumulate in and are obstructed by forests and trees.

Again,

"In proportion as countries previously malarious are cleared up and thickly settled, periodical fevers disappear."

Here he points out that in such cases the land is cultivated and its swamps and pools are drained so that mosquito-breeding places are abolished. He further states that as the forests and underbrush disappear before the implements of the agriculturist colonies of 
mosquitoes wafted by winds are not obstructed and are accumulated by foliage. Again, the fact that malaria usually keeps near the surface of the earth and is said to "hug the ground" or "love the ground" corresponds once more to the habits of mosquitoes.

It will be unnecessary to take up any of the further points, except to quote two significant paragraphs as follows:

In opposition to the mosquital origin of malarial disease it is known that numerous mosquito wounds may be inflicted without the occurrence of malarial disease; but this is by no means ineompatible with the theory. We do not yet know whether the poison be mosquital saliva or whether the fever-producing element be a bacillus with which the puncturing proboscis of the insect may be loaded at the time of inflicting its wounds. The scratch of a lancet will not produce vaccinia unless the instrument be charged with vaccine matter; the puncture-needles of Pasteur would be harmless and impotent, did he not load them with infecting bacteria; so with dog-bites and hydrophobia, etc.

\section{Again :}

Nay, it may even turn out that, under certain circumstances, mosquito-bites shall even be protective against malarial disease, for as Pasteur and others are able to produce, artificially, "attenuated culture-fluids," the inoculation of which, while producing slight symptoms, protects from more serious phases of disease, so may there exist in nature naturally "attenuated" fever-poison fluids, the inoculation of which, by mosquital puncture, may produce trivial symptoms, and thus protect from more decided attacks of veritable fever.

In the first of these paragraphs Dr. King fully meets the objection which curiously enough is raised to-day in the Bitter Root $\nabla$ alley in Montana by the inhabitants who claim to disbelieve the so-called theory of the tick-transmission of the Rocky Mountain spotted fever. "Why," they say, "We have been bitten by ticks many times and have never had the fever." As King pointed out in these early days, they have not been bitten by an infected tick.

In the second paragraph he almost anticipates Koch's conclusions as to the immunity of native children in German East Africa, even though he does not point out their danger as reservoirs.

It may be well to quote still another paragraph which is of especial significance:

In so far, therefore, as regards the geograph. ical relation between mosquitoes and malarial disease, it may be said: (1) The two often coexist; (2) there is no decided proof that localities alleged to be exempt from ague are also exempt from mosquitoes; (3) there is no locality noted for malarial disease where mosquitoes do not exist.

Very naturally, in conclusion, the farsighted author mentions the question of prophylaxis on the basis of his theory. $\mathrm{He}$ points out protection to the individual during the evening and night by gauze curtains, window-screens or clothing impenetrable to their probosces, or an anointment of the body with some liniment; protection to the domicile by screens or fences, or light traps, or the use of smoke such as pyrethrum, or of a volatile oil; municipal protection by the destruction or draining of swamps and pools, etc.

It will thus be seen that malarial prophy. laxis has made practically only one step since the days of King, except in so far as measures are concerned which depend upon the now known biological peculiarities of malarial species. His system included everything which was done in Italy for many years after Ross's discovery and which resulted in the lowering of the percentage of malaria on the Roman Campagna from 74 to 14, and his only omission from the present system is that of quininization of the people at large as practised by Koch in East Africa and by the late Dr. Celli and his colleagues in Italy to-day.

It is strange that so suggestive a paper as this and, in fact, one so theoretically conclusive, should have been received with so little interest and have been so soon forgotten. That Dr. King was a strong man is shown by the fact that he was not in the least discouraged by his interview with so renowned an entomologist as Riley, or by the lukewarm interest with which his original paper was received by the Philosophical Society of Wash- 
ington, but went on and prepared it in its final form for publication in The Popular Science Monthly.

There was little published comment, and it was not until 1899, sixteen years later, that Dr. Geo. H. F. Nuttall, now of Cambridge University, England, in his classical paper "On the Rôle of Insects, Arachnids and Myriapods as Carriers in the Spread of Bacterial and Parasitic Diseases of Man and AnimalsA Critical and Historical Study," published as one of the Johns Hopkins Hospital Reports, Vol. VIII., Nos. 1 and 2, that the full force of King's argument began to be appreciated. Nuttall here incorporated practically all of King's arguments and added many data gathered from other writers as well as his own, and, as he has since publicly stated and as he has personally remarked to me, it is remarkable that the 1883 paper was not soon followed by critical investigation. As has been shown so many times since, however, and strikingly in the case of Sambon's insistent claims for the carriage of pellagra by Simulium, a theory in no way comparing to King's for the soundness of its basis, conclusions based on epidemiological findings or upon coincidences are always dangerous. Where the range of a suspected host coincides with the range of a disease, it is possible or even probable that the suspected host may have some relation to the disease, but of course transmission experiments are necessary for absolutely definite conclusions.

And so it happened that, apparently without knowledge of King's paper, but based upon his own work in the transmission of filariasis by Culex and upon the then recognized transmission of the causative organism of Texas fever of cattle (sometimes called bovine malaria) by a tick as demonstrated by Smith and Kilbourne, Manson suggested to Ross the necessity for accurate laboratory work on malaria with mosquitoes as possible hosts. How triumphantly Ross carried out this magnificent piece of research is known to all the world, but it is a pity that it had not been done years earlier. Of course the laboratory technique in 1883 was not what it was in 1897 , and of course, although Laveran had already discovered the Plasmodium malarice, practically nothing was known of its life-cycle in 1883 , but is it not possible, indeed is it not probable, that, had our fellow member, Doctor King, possessed the laboratory facilities and the technique at the time when he was so full of his great idea, he would have solved the problem, would have confirmed his anticipations, would ultimately have received the Nobel prize, and would have gone down to history as one of the greatest benefactors of the human race?

\section{U. S. Department of Agriculture}

L. O. Howard

\section{THE COMMITTEE OF ONE HUNDRED ON SCIENTIFIC RESEARCH OF THE AMER- ICAN ASSOCIATION FOR THE ADVANCEMENT OF SCIENCE}

THE committee held its second meeting in Houston Hall, the University of Pennsylvania, Philadelphia, on the afternoon of December 28, 1914. Mr. Pickering was in the chair, and the other members present were:

Messrs. E. W. Brown, Franz Boas, J. McK. Cattell, A. D. Cole, Edwin G. Conklin, Chas. R. Cross, Chas. B. Davenport, H. L. Fairchild, Karl E. Guthe, Ross G. Harrison, L. O. Howard, George E. Hulett, Chas. S. Howe, W. J. Humphreys, W. W. Keen, Frank R. Lillie, D. T. MacDougal, C. F. Marvin, C. L. Mees, George T. Moore, T. H. Morgan, Herbert V. Neal, Edward L. Nichols, E. B. Rosa, Wm. T. Sedgwick, Frank Schleslinger, Edgar F. Smith, Henry B. Ward and Arthur G. Webster.

After a statement by the secretary and introductory remarks by the chairman, the committee listened to reports from the subcommittees on research funds, on research in educational institutions, on the selection and training of men for research, on the promotion of appreciation of research and on plans for the subcommittee on research in industrial laboratories. Each of the reports was fully discussed, most of the members of the committee in attendance participating.

On the recommendation of the executive 